Preprint version. Final version appeared in International Journal of Sustainability in Higher Education, 2012, 13(3), pp 219-231: http://dx.doi.org/10.1108/14676371211242544

\title{
The University and Transformation Towards Sustainability
}

\section{- the strategy used at Chalmers University of Technology}

\author{
John Holmberg, Ulrika Lundqvist, Magdalena Svanström and Marie Arehag, \\ Chalmers University of Technology, SE 41296 Göteborg, Sweden
}

\begin{abstract}
Purpose: In this paper, the strategy used for achieving change towards sustainability at Chalmers University of Technology (Chalmers) is presented. Examples of how this strategy has been used are described and discussed, and exemplified with different lines of activities in a project on Education for Sustainable Development, the ESD project.

Design/methodology/approach: The strategy consists of three important building blocks: 1) Create a neutral arena; 2) Build on individual engagement and involvement; 3 ) Communicate a clear commitment from the management team. The analysis is made along three different lines of activities in the ESD project: 1) The work to improve the quality of the compulsory courses on sustainable development; 2) The efforts to integrate ESD into educational programmes; and 3) The work to collect and spread information on good teaching practices within ESD. Some other related examples where the strategy has been applied are also presented.

Findings: The ESD project functioned as a neutral arena since it was not placed at any specific department but rather engaged participants from many departments. This neutral arena has been important, e.g. to increase the willingness of teachers to share their good teaching examples. The process was successful in creating a shared responsibility and for starting learning processes in many individuals by the involvement of a broad range of educational actors at Chalmers. The strong and clear commitment from the management team has worked as a driving force.
\end{abstract}

Originality/value: This paper can provide valuable input to universities that struggle with change processes.

Keywords: curriculum greening, education for sustainable development, ESD, university, change, transformation

\section{Introduction}

Many universities struggle with change processes (Ferrer-Balas et al., 2004; Hopkinson, 2010; Jansen et al., 2005; Kamp, 2006). There are many good ambitions and goals that seem to be hard to implement, e.g. equality, integration of the different aspects of the knowledge triangle (education, research and innovation) or implementation of education for sustainable development (ESD). Transforming higher education contents and practices is a tough challenge, and actual results are still far from the desired image of a higher education for sustainable development (SD) (The Observatory, 2006; Holmberg and Samuelsson, 2006).

Over the years, Chalmers University of Technology (Chalmers) has developed a strategy for this kind of more complex change processes. It has been used for promoting the inclusion of sustainable development in university activities on a broader scale and more specifically to accelerate the implementation of ESD. The strategy has also been used to enhance collaboration across disciplines and with the surrounding world through eight newly introduced 'Areas of Advance'. The aim of this paper is to describe the strategy that has been used, describe how it relates to preceding and on-going processes as well as future ambitions, describe achievements and lessons learned in this process and discuss barriers and drivers, in 
Preprint version. Final version appeared in International Journal of Sustainability in Higher Education, 2012, 13(3), pp 219-231: http://dx.doi.org/10.1108/14676371211242544

order to provide input to other universities that struggle with change processes. In this paper, we will illustrate the strategy by describing a specific three-year reform project, which started in 2006, with the goal to accelerate the implementation of ESD at Chalmers.

The ESD project is part of a long series of processes related to SD and ESD at Chalmers. Already in 1985, a policy was introduced stating that educational programmes should contain a course load corresponding to five weeks of full-time studies on environment and SD (E\&SD). Since 2003, this has been a compulsory requirement. In 1989, Chalmers started a process, which lead to the formation of The Gothenburg Centre for Environment and Sustainability (GMV). The centre is now an open and cross-disciplinary network for researchers at Chalmers and Gothenburg University and has been an important driver for development of education and research on SD at Chalmers. It has carried the history in this area across shifts in university management. In 2006, Chalmers received a UNESCO chair in ESD, and the university management approved funding of the connected ESD project. Strongly related to this process is also the series of international conferences organized by Chalmers and Gothenburg University, starting with a workshop on ESD within the EU summit in 2001.

The aim of the ESD project was to develop an organization that can manage the implementation of ESD at Chalmers, resulting in a suggestion that:

- guarantees and continuously enhances the quality of the compulsory courses on E\&SD,

- guarantees and continuously enhances the quality of SD content in other courses,

- effectively gives support to those who order SD courses,

- effectively gives support to students when choosing SD courses,

- effectively promotes internal and external information exchange on ESD,

- effectively promotes cooperation with internal and external stakeholders within ESD,

- provides a forum for meetings for students and for teachers with interest in the area,

- provides support to further education within the SD area for non-teaching personnel,

- provides support to the development of a campus reflecting Chalmers initiative for SD.

There are approximately 12,000 students at Chalmers. Most of the students study for a Master of Science in Engineering degree, which are five-year long programmes in different disciplines, such as chemical, mechanical, electrical, computer engineering etc. Chalmers also admit students to the last two years of these programmes for a Master degree. There are also Architect and Teacher degrees (five-year long programmes) and Bachelor of Science in Engineering programmes (three-year long).

The analysis of the change process in relation to the strategy that is described in the next section is made in the subsequent section along three different lines for the ESD project: The work on the compulsory courses, the efforts for integrating ESD into educational programmes, and the work to collect and spread information on good teaching practices within ESD. More information on the project can be found in the literature (Holmberg and Arehag, 2007; Holmberg et al., 2008) and on www.chalmers.se/gmv/EN/projects/esd_chalmers. Other change processes than the ESD project in which the same method has been used will also be briefly discussed.

\section{Method: Chalmers' strategy for change}

To implement new ideas and achieve change at universities, with their high degree of autonomy and strong traditions, is often a difficult mission, especially if the mission is as complex as to achieve a higher degree of embedding of ESD at the university. A task like this often turns into something that is in everybody's interest but is nobody's responsibility. One way to get around this dilemma is to use a top-down demand and control strategy, more often used in business organisations. Kotter (1995), suggests that a successful change process in a business organisation goes through a series of eight distinct stages: Establishing a sense of 
Preprint version. Final version appeared in International Journal of Sustainability in Higher Education, 2012, 13(3), pp 219-231: http://dx.doi.org/10.1108/14676371211242544

urgency; Forming a powerful guiding coalition; Creating a vision; Communicating the vision; Empowering others to act on the vision; Planning for and creating short-term wins; Consolidating improvements and producing still more change; and Institutionalizing new approaches. Our experience is that these kinds of sequenced processes can work well for hierarchal organisations (like an enterprise), but meet obstacles when introduced on a broader scale at a university, since it requires very effective incentives in order to profoundly affect every-day university practices. Such incentives are difficult to construct for complex issues, as for instance the embedding of ESD. Another way to go about is that a certain department is given the task or takes on the mission on its own. This might work to a certain degree, but often leads to lock-in effects in the long run. This lock-in can consist in that persons in the rest of the organization do not make an effort since they can leave the concern to the responsible department. The responsible department might also feel that they want to be in control and therefore does not welcome initiatives from other departments or individuals. When funding comes with the responsibility, the risk that this happens is even greater. At a university, the power structure is more complex than in an enterprise. The top management has power but so has also, and in many cases to a larger extent, all the teachers and scientists at the university. In such structures, it is essential to be able to create engagement and involvement among the staff in order to succeed with broad-scale transformation. It is our experience that the facilitation of the change process by a neutral arena/organization is also crucial.

Hopkinson (2010) used a sequenced process developed for the Harvard campus greening initiative for transforming the University of Bradford in a process named Ecoversity. In a campus greening project, the hierarchal structure can be quite clear also at a university, but when Hopkinson applied the method on a broader scale at the university, it met some obstacles. It was perceived as being mainly a top-down estates-driven programme, involving a number of small 'bitty' projects. Based on these findings it was decided that a new approach would focus on the decision-making processes, cross institutional action-based task groups, and the engagement and involvement of students and staff.

Scott (2003), in a paper focusing mainly on the need for universities to change their pedagogical methods in light of new opportunities and shifting needs, presents some ideas on how to achieve change. These ideas are generic enough to be applicable also to other change processes at university. He reports on key insights from his own practice and from screening the scientific literature. He argues that "Change is learning and learning is change" - and that motivation is what fuels both individuals and organizations to learn and thereby change. Furthermore, he emphasizes the very strong connection between individual learning and organizational learning - change in both university mission, systems and infrastructure and the motivation and capabilities of individuals must therefore be addressed simultaneously and be mutually supportive. He also states that team-efforts that are action-research based and cyclical rather than linear are the most successful.

At Chalmers, a method for achieving change has been identified that is clearly supported by the work by others reported in literature. The strategy has now been tested on different scales and for many years and seems to be successful. Three important building blocks can be identified in Chalmers' strategy for achieving change:

1. Create a neutral arena/organization: Some kind of neutral arena that can facilitate the change process is needed. It must have an overview of the whole organisation and must be working across research groups to avoid lock-in effects. It must function as a platform for cooperation and information exchange and be of long-term character. An arena like this is essential for making this kind of complex change successful and for it to have long-lasting effects. Such an organisation can function as a driver for the issues that otherwise often become everyone's interest but no-one's responsibility. Important features of this arena/organisation are that it is: open and inviting, serviceoriented (not building its own empires), building trust and lowering barriers, keeping the memory of the change process, and giving feed-back to relevant stakeholders and thereby keeping up the momentum of change. 
Preprint version. Final version appeared in International Journal of Sustainability in Higher Education, 2012, 13(3), pp 219-231: http://dx.doi.org/10.1108/14676371211242544

2. Build on individual engagement and involvement (bottom-up): Universities, with their core values of scepticism, curiosity and freedom of speech, have a high degree of autonomy, which must be respected in a change process. Teachers hate to be taught! The change process must therefore build on the engagement and involvement of individuals. The features of the neutral arena/organisation and the methods used to bring about change must use this as a core principle.

3. Communicate a clear commitment from the management team: The change process must be in line with the overall strategy of the university. Ideally it should be an essential part of the vision of the university. It must not be counteracted by different structures in the organizational system. It is important that the university clearly motivates the change process - systematically creates incentives and other structures that correlate with and pushes for the change process.

\section{Transformation processes in relation to Chalmers' strategy for change}

In this section, three transformation processes related to the ESD project will be discussed in relation to the three building blocks of Chalmers' strategy for change. These examples target different elements of the overall vision to enhance the quality and embedding of ESD at the university and to create a permanent platform for further work on ESD. The basic course requirement for SD and the integration of ESD into educational programmes were addressed with the purpose of increasing quality, engagement and competences, whereas the collecting of good teaching practices was seen as important in providing support to the first two elements. Some other transformation processes, in which Chalmers' strategy for change has been used, will be discussed at the end of the section. The aim is to illustrate how the strategy has been put into practice.

\subsection{The compulsory courses on E\&SD}

All students at Chalmers are required to take a 7.5 hec course (five full-time weeks of studies) in E\&SD in their programmes. A variety of courses have been developed during the years at different departments without any formal discussions or directives on appropriate content or intended learning outcomes. Early in the ESD project, a need was identified to improve the quality of many of these courses. One concrete result from this part of the ESD project is a two-page document describing recommendations of learning outcomes for the compulsory courses in E\&SD at Chalmers. The learning outcomes are formulated in such a general way that they can be applied at all the engineering disciplines at Chalmers. These learning outcomes are partly described in Segalàs et al (2009). The process to develop these guidelines has been at least as important in the overall change process towards improved quality of the $\mathrm{E} \& \mathrm{SD}$ courses as the resulting text itself.

Initially, inventories of the content of existing courses were made. In order to stimulate teacher engagement, individual meetings were held with teachers and programme directors in order to gather the information needed (Lundqvist and Svanström, 2008). The inventories gave the present state of content, credits, place in curriculum, types of teaching and learning activities, assessment methods, and the students' opinions of the quality. Both the process of making and the results of the inventories were used to support also other goals in the project, e.g. the inventories involved programme-wise discussions with different teachers to provide an overview also to them and results have been presented to educational leaders at Chalmers, pointing out the need of improvements.

After the inventories had been performed, the teachers in the compulsory courses were invited to seminars, with the purpose of discussing and improving a preliminary version of the guideline text. There were several purposes of these seminars, but most importantly, they functioned as a neutral meeting place for teachers who do not regularly meet since they are at different departments at Chalmers. This network of teachers that was created through the seminars was also used for exchanging experiences and thoughts around ESD as support in improving the quality of courses and programmes and in order to create a common view and a shared sense of responsibility. 
Preprint version. Final version appeared in International Journal of Sustainability in Higher Education, 2012, 13(3), pp 219-231: http://dx.doi.org/10.1108/14676371211242544

The ESD project also organized a seminar to which a broad range of stakeholders at Chalmers were invited. The aim of this seminar was to discuss quality issues around ESD and to show that the quality of courses is not just a concern of the individual teacher but a concern for all stakeholders, from the students to the top management of the university and also for external stakeholders such as industry. The seminar included a presentation by student representatives about the students' expectations and, not always so positive, evaluations of the E\&SD courses. This seminar functioned as a neutral meeting place, across departments and stakeholder groups, since it was initiated and organized by the neutral body of the ESD project. It also gave an opportunity for the top management to show their commitment.

The process of formulating the guidelines was a necessary step in order to create a shared view of learning outcomes of the compulsory courses in E\&SD. In turn, this was necessary to increase the quality of the courses. The guidelines can be used as support for teachers and programme directors when developing courses and programmes. The process was successful in creating a shared responsibility and for starting learning processes in individuals involving a broad range of educational actors at Chalmers.

It is important to be aware of that reform processes take time and therefore to allow for a continuation also after a project ends. The process of formulating guidelines for the compulsory courses in E\&SD at Chalmers actually started before the ESD project, in 2004, and has since then continued in an iterative process including several rounds of evaluations of the courses, discussions with the teachers, and new versions of the guidelines (the latest version in 2009). A further need for development of the guidelines has been pointed out, e.g. to better include economic aspects of SD (Hanning et al., 2010). The ESD project also aimed at creating good conditions for a continued enhancement of quality of the E\&SD courses. The continued work can partly be handled by the present educational organization at Chalmers, but the ESD project also identified a need of an additional organizational body that should have responsibility for the continuous development of the guidelines based on state-of-the-art and for providing support to teachers and programme directors, e.g. through seminars and professional development courses.

\subsection{Integrating ESD into educational programmes}

Embedding of ESD into educational programmes and mainstreaming of SD at a university is a very difficult task. It requires a shift of mindsets so that the paradigm that underlies both research and educational programmes is that SD is promoted in the best possible way and precautions are taken that research and education is not leading in the wrong direction. It requires that researchers and teachers understand their important role in relation to a responsible development and management of technology and a responsible approach to new research results.

In order to achieve embedding of SD at the university and integration of ESD into educational programmes, the most important target areas to influence are people and structures. The commitment and competences of people that are in the organization on a longterm basis have to be increased in order for any effort to have a profound and long-lasting effect. Furthermore, structures in the educational organization may constitute both a barrier to and a driver for such change. It is therefore important that these structures are analyzed so that they can be utilized and if needed changed in order for embedding efforts to become effective and even continue to push for improvements continuously.

In order for teachers and programme directors to be able to participate in the integration of ESD into educational programmes, they first need to be convinced that this is important and they also need support in making the necessary changes. Within the ESD project, a so-called "resource group" was put together, containing teachers that were experienced in ESD work but that belonged to different parts of the organization. This group was given the task to develop and use methods for integration of ESD into educational programmes at Chalmers. The group carefully analyzed earlier work that other universities had performed, and the supporting structures and on-going change processes at the university, and came up with a method that built on the Individual Interaction Method (IIM) that had been developed and 
Preprint version. Final version appeared in International Journal of Sustainability in Higher Education, 2012, 13(3), pp 219-231: http://dx.doi.org/10.1108/14676371211242544

used at TU Delft (Peet et al., 2004). The new method contained two major elements: programme workshops for faculty, and individual coaching discussions. The work of the resource group is described in more detail elsewhere (Svanström et al., 2010). Since, teachers seem to be reluctant to accept educational efforts directed towards them ('hate to be taught'), the main idea with IIM is instead to interact on an individual level. By interviewing the individual teachers about their courses and discuss how the topics relate to SD and how this can be further improved, the teachers are still in control of their courses and the experience is that they will open up for change and embedding of ESD in a much better way. Asking teachers about their ideas also ensures that the discussion is kept at an appropriate level and on topics that stimulate interest and further learning.

Selecting ESD experts to participate in the resource group from different parts of Chalmers, with the aim that their competences and legitimacy would cover the whole organization, built on the idea that a neutral organization is needed. In fact, the goal was even to avoid that this group was ever perceived as having responsibility for integration of ESD in educational programmes. The method that was developed built on the idea that the change process has to be the responsibility and initiative of programme directors and teachers and not of the resource group, but that the resource group should be available to provide support in the change process. Furthermore, the group functioned as a driver for the work since they regularly reminded the different groups about the intentions, the important incentives and support available in the integration work.

The method that was developed by the resource group aimed at building individual engagement and involvement. The group spent a lot of time on trying to understand what incentives or barriers that exist for the different actors in taking on this responsibility and performing the necessary changes. The task to motivate for change was as important as providing support in the change process. Building on the experiences from the IIM, developed and used at TU Delft, it was seen as important to initiate learning processes in individuals by starting with discussions on how their competences and topics are important for SD and ESD, thereby triggering an increasing interest and commitment for integration of ESD in courses and programmes. Furthermore, hitch-hiking with other processes of change was identified as important, e.g. the different ways that the university at the time was adapting to the Bologna process and the CDIO framework. The reason for this was that there is always a risk for change fatigue in the organization after considerable reforms have been made, but adding on another element during the actual change process might not even lead to extra work. Respect for the role and work load of individuals and their importance in effecting in changes is thus an important principle in this work.

The commitment from the management team at Chalmers is clear. The strong vision: Chalmers - for a sustainable future, has even been a bit provocative to some people, but clearly shows the very strong commitment from the management level. This, along with other pressure from even higher levels, e.g. the Higher Education Act and the degree ordinances that require that all activities at universities promote $\mathrm{SD}$ and that all engineers are provided with the competences needed in order to manage technologies in a sustainable way, have been utilized as motivating arguments in the process. The commitment from the university management should ideally also spread throughout the organization so that appropriate control measures and incentive systems are put in place. Advice has been put forward to the educational management from the ESD project on how to improve the control system for ESD in the annual quality review process at the university that will regularly remind the different actors on the importance of integration of ESD.

\subsection{Good teaching practices}

Early on in the ESD project, a need was identified among teachers, for good examples of ESD teaching practices that could be used as inspiration in fulfilling the needs of a quality increase in ESD. The ESD project therefore intended to create a system for collecting and spreading of such examples. 
Preprint version. Final version appeared in International Journal of Sustainability in Higher Education, 2012, 13(3), pp 219-231: http://dx.doi.org/10.1108/14676371211242544

Initially, different methods for systematic collection and spreading of good examples were investigated. The option to use a web portal was assessed in a thorough survey. Several such web portals exist but they all require a lot of support in order to stay up-to-date in terms of content and functions. The idea of a web portal was therefore abandoned, mainly because it would require too large resources to support and a long-term commitment (Ottosson and Palme, 2008). Instead, good teaching practices were to be described and collected in a pdf document which could potentially be updated and complemented over time. A template was developed for presenting good examples in just one page. The template includes instructive headings in order to make it possible for teachers to fill in information about their good examples themselves. In all, 29 good examples of different types of teaching practices were collected, which have been published in a report that is now a resource available through the internet. The examples covered minor parts of courses, whole courses, and even a whole educational programme (Palme, 2009; Palme, 2010).

The teachers were willing to share their examples but it turned out to be difficult for them to take the time needed to fill in the template, and therefore interviews turned out to be the most efficient way to get the information from the teachers. The project leader then filled in the template and finally got approval of the text from the teacher. The incentives for teachers to spend their time to share good examples are lacking. In research, incentives to share results are very clear and relevant for the individuals. This is not the case in education. In order to increase the engagement of teachers, some kind of reward system should be implemented, e.g. connected to the promotion system at the university. The integration of ESD issues into the promotion system can be a signal of commitment from the university management.

One conclusion from this activity is that there has to be individual engagement among teachers for them to be willing to share and put time on sharing their good examples with others. To ensure a continuous collection and spreading of good examples, there has to be a responsible body at the university. It is advantageous if this responsibility is put on a neutral body - to ensure a broad collection and spreading that involves all departments at the university. There was a suggestion from the ESD project to continually collect good examples through pedagogical development project courses for teachers at Chalmers.

\subsection{Other examples}

This paper has so far focused on transformation processes related to the ESD project performed in 2006 to 2009. Chalmers' strategy for change has also been applied for the early acceleration of the education and research within the field of E\&SD in the late eighties, and later for implementing SD as a driving force for the whole university. Recently, the same strategy has been used in forming Chalmers Learning Centre and eight so-called Areas of Advance, and for building five knowledge clusters, together with the private and public sector, for testing new ideas and implementing sustainable development in the region of west Sweden.

In order to accelerate education and research within the field of $E \& S D$, the university management took some important steps. The first was a policy launched in 1985 to introduce compulsory courses in the field of E\&SD at the bachelor level for all students. Later, it was also decided that all students should have the option to continue the studies in this direction at Master level. This was done instead of implementing a special Bachelor of Engineering programme on E\&SD that would only be available to some students. Another important step, in 1989, was to create an immaterial organization, a neutral arena, in the field of E\&SD - The Gothenburg Centre for Environment and Sustainability (GMV). This decision resulted in that faculty members could utilize this arena and still be working in their traditional department. At the arena, they met scientists with similar interests, but often with different background, and also external stakeholders. New ideas were explored and new fields of research were created. Quite soon, GMV attracted 400 scientists. The decision to form GMV was important in creating engagement within the field and also to avoid look-in-effects that can arise if instead one department takes the lead in SD within the university. This strategy had the effect that the field of E\&SD became one of the strongest fields at the university and lead to further 
Preprint version. Final version appeared in International Journal of Sustainability in Higher Education, 2012, 13(3), pp 219-231: http://dx.doi.org/10.1108/14676371211242544

initiatives: in 1999, Chalmers launched the Chalmers Environment Initiative of 100 million SEK, with 7 new professor chairs that were spread over the whole university; in 2001 Chalmers became a member of the Alliance for Global Sustainability (AGS) together with MIT (Cambridge, USA), ETH (Zürich, Switzerland) and Tokyo University (Tokyo, Japan).

In 2009, after the ESD project, Chalmers Learning Centre was launched as a new neutral arena for improving the quality of learning activities at Chalmers. The Centre has the responsibility to push for development of ESD and other facets of learning at the university and builds on the experiences from the ESD project and from other earlier initiatives in the field of learning. The Centre is an arena for collaboration between many different actors and activities and it aims at facilitating cooperation and pushing for change both in terms of competences of teachers, of quality of educational programmes and in terms of enabling structures in the organization. It makes an effort to stimulate individual engagement, e.g. by promoting a Scholarship of Teaching and Learning (a scholarly critical reflection of practitioners of education) in order to achieve long-term and continuous competence development among teachers. The formation of the Centre is a sign of the very strong commitment for ESD and for learning at Chalmers. To ensure that learning and ESD is always on the agenda, the director of the Centre is a member of the educational management team.

In order to enhance SD as a driving force for the whole university, Chalmers launched, also in 2009, a matrix organisation, with eight so-called Areas of Advance (Energy, Transportation, Built environment, Life sciences, Nano technology, Materials, Information and Communication Technology, and Production). In an Area of Advance, research, education and innovation activities at Chalmers that are linked to the theme of the Area become visible to each other and to the surrounding world. This makes it much easier for efficient collaboration within Chalmers and with other universities and industry and other external groups. The individual faculty members are still members of their department, but also active and visible in the Area of Advance (the same idea as for GMV). Each Area of Advance constitutes a neutral arena within their field.

The strategy is now used also to build regional knowledge clusters together with industry and the surrounding society. Since the university is often more stable in the region than industry is and since the university is the only actor with all three components in the knowledge triangle: education, research and innovation, it is natural that the university takes on a special role in building these clusters in a neutral, open and inviting way. In the autumn of 2011, five knowledge clusters were launched in the region of west Sweden (Urban Future, Marine and Maritime, Bio based products, Sustainable Mobility, and Life sciences). All five clusters were identified by the highest level of the academy, and the private and public sector in the region. At present, these neutral arenas are being shaped with involvement from academia and the public and private sector in order to build trust and create engagement, creativity and attractiveness for a real change towards sustainability.

\section{Concluding remarks}

The strategy used for achieving change at Chalmers University of Technology has been presented and illustrated using a project on Education for Sustainable Development (ESD) and other change projects.

The three important building blocks of the strategy are:

1) Create a neutral arena/organization - The ESD project functioned as a neutral arena since it was not placed at any specific department but rather engaged participants from many departments. This neutral arena has been important, e.g. to increase the willingness of teachers to share their good teaching examples.

2) Build on individual engagement and involvement (bottom-up) - The ESD project was successful in creating a shared responsibility and for starting learning processes in many individuals by the involvement of a broad range of educational actors at Chalmers.

3) Communicate a clear commitment from the management team - The strong and clear commitment from the management team has been used as a driving force in the ESD project. 
Preprint version. Final version appeared in International Journal of Sustainability in Higher Education, 2012, 13(3), pp 219-231: http://dx.doi.org/10.1108/14676371211242544

The paper can provide valuable input to universities that struggle with change processes.

It is difficult to measure the benefits of the strategy but it seems to have provided good results, e.g. by reducing lock-in effects that would otherwise have slowed down or halted development, and for building trust and lowering barriers in the organisation. The aim of this paper has mainly been to inform about the strategy and illustrate its elements by describing processes in which it has been applied. Future studies should compare the strategy with other strategies having the same goals and try to provide a more thorough analysis of its characteristics and benefits and shortcomings.

\section{References}

Björneloo I. and Nyberg E. (Eds.) (2007), Drivers and Barriers for Implementing Learning for Sustainable Development in Pre-School through Upper Secondary and Teacher Education. UNESCO Technical Paper $\mathrm{N}^{\circ} 4$, February.

Ferrer-Balas D., Bruno J., de Mingo M. and Sans R, (2004), “Advances in education transformation towards sustainable development at the Technical University of Catalonia, Barcelona" International Journal of Sustainability in Higher Education, Vol. 5 No. 3, pp.251-266.

Hanning A., Priem Abelsson A., Lundqvist U. and Svanström M. (2010), working paper, Chalmers University of Technology, Sweden.

Havström M., Magnusson K. and Ottosson P. (Eds.) (2007), The Right to Knowledge - Public Learning for Sustainable Development, Laboratory for Democratic Learning, October 1113, Gothenburg.

Holmberg J. and Samuelsson B. (Eds.) (2006), Drivers and barriers for implementing sustainable development in higher education. Technical paper No 3, UNESCO Education Sector.

Holmberg J. and Arehag M. (2007), “A Systems Approach to Transforming a University into more Sustainability" paper presented at World Environmental Education Congress, 2-6 July, Durban, South Africa.

Holmberg J., Svanström M., Peet D.-J., et al. (2008), "Embedding sustainability in higher education through interaction with lecturers: Case studies from three European technical universities", European Journal of Engineering Education, Vol. 33 No. 3, pp.271-282.

Hopkinson, P. (2010) "Ecoversity: the potential for sustainable development to reshape university culture and action", Int. J. Environment and Sustainable Development, Vol. 9, No. 4, pp.378-391.

Jansen L., Holmberg J. and Civili F. S. (2005), International Evaluation of UPC Environmental and Sustainability Research and Education, UPC, Barcelona, available at: http://www.upc.es/mediambient/UPCSostenible2015.html.

Kamp L. (2006), "Engineering education in sustainable development at Delft University of Technology", Journal of Cleaner Production, Vol.14, pp.928-931.

Kotter, J. P. (1995) "Leading change: why transformation efforts fail", Harvard business review, March-April 1995, pp. 57-67.

Lundqvist U. and Svanström M (2008), "Inventory of content in basic courses in environment and sustainable development at Chalmers University of Technology in Sweden", European Journal of Engineering Education, Vol. 33, pp. 355-364.

The Observatory (2006). The Observatory. Status of engineering education for sustainable development in European higher education, available at: www.upc.edu/eesd-observatory.

Ottosson P. and Palme U. (2008), Rapport "Goda exempel" - En webbportal som presenterar goda exempel på undervisning för hållbar utveckling - en bra idé?, Chalmers University of Technology, Sweden (in Swedish).

Ottosson, P. and Samuelsson, B. (Eds.) (2009), The Gothenburg Recommendations on Education for Sustainable Development, The Centre for Environment and Sustainability (GMV), Chalmers University of Technology/University of Gothenburg, Sweden.

Palme U. (2009), Undervisning i och om hållbar utveckling - 29 olika Chalmersexempel, Chalmers University of Technology, Sweden (in Swedish). 
Preprint version. Final version appeared in International Journal of Sustainability in Higher Education, 2012, 13(3), pp 219-231: http://dx.doi.org/10.1108/14676371211242544

Palme U. (2010), "Good examples of education for sustainable development at Chalmers: achievements and limitations", paper presented at Engineering education in sustainable development, Sep19-22, Göteborg.

Peet D. J., Mulder K. F. and Bijma A .(2004), "Integrating SD into engineering courses at the Delft University of Technology: the individual interaction method", International Journal of Sustainability in Higher Education, Vol. 5 No. 3, pp. 278-288.

Pramling Samuelsson I. and Kaga Y. (Eds.) (2008), The contribution of early childhood education to a sustainable society, UNESCO, Paris.

Segalàs, J., Ferrer-Balas, D., Svanström, M., Lundqvist, U., Mulder, K.F., 2009. What has to be learnt for Sustainability? A Comparison of Bachelor Engineering Education Competences at three European Universities. Sustainability Science 4, 17-27.

Scott G (2003). Effective change management in higher education, Educause review, November/December: 64-80

Svanström M., Eden M., Nyström T., Palme U., Carlson O. and Knutson Wedel M. (2010), "Embedding of ESD in engineering education - experiences from Chalmers University of Technology", paper presented at Engineering education in sustainable development, Sep 19-22, Göteborg.

John Holmberg, Professor in Physical Resource Theory and vice president at Chalmers University of Technology. He also holds an UNESCO-chair in Education in sustainable development.

john.holmberg@chalmers.se

Physical Resource Theory, Chalmers University of Technology, SE-412 96 Göteborg, Sweden

John Holmberg obtained his PhD in Physical Resource Theory at Chalmers

University of Technology in 1995. He has been professor at Chalmers since 2006 and received his UNESCO chair the same year. He is member of UNESCO expert panel for the UN decade for ESD; he is member of the Interim Steering Committee for the Global University Partnership on Environment for Sustainability; he is member of the editorial board to the international journal of Industrial Ecology; member on the board of Swentec, Swedish Environmental Technology Council; member of the steering committee of the Balaton Group; and chairman of the jury for the Gothenburg award for sustainable development. His main research focus is on: goal conflicts between wellbeing and sustainable development; strategic planning for sustainable development (backcasting); institutional transformation; and innovation.

Ulrika Lundqvist, PhD in Physical Resource Theory and University Lecturer at Chalmers University of Technology

ulrika.lundqvist@chalmers.se

Physical Resource Theory, Chalmers University of Technology, SE-412 96 Göteborg, Sweden

Ulrika Lundqvist obtained her PhD in Physical Resource Theory at Chalmers University of Technology in 2000. Ulrika's research interests focus on sustainability indicators and sustainable product development. Ulrika is also engaged in issues on education for sustainable development.

Magdalena Svanström, Associate Professor in Chemical Environmental Science at Chalmers University of Technology, and Director of Chalmers Learning Centre 
Preprint version. Final version appeared in International Journal of Sustainability in Higher Education, 2012, 13(3), pp 219-231: http://dx.doi.org/10.1108/14676371211242544

magdalena.svanstrom@chalmers.se

Chemical Environmental Science, Chalmers University of Technology, SE-412 96 Göteborg, Sweden

Magdalena Svanström obtained her PhD in Chemical Environmental Science at Chalmers University of Technology in 1997 and did a PostDoc at Massachusetts Institute of Technology in 2001. She has been an Associate Professor at Chalmers since 2005. Today, Magdalena's research interests focus on sustainability assessment as a means of guiding in product development, and on education for sustainable development. As the Director of Chalmers Learning Centre, her role is to provide a platform for collaboration aiming at improving the conditions for learning in university-related activities, e.g. in terms of supporting a culture of scholarship of teaching and learning among practitioners. She is a member of the UNECE expert group on educator competences for education for sustainable development. She has authored a text book on sustainable development for engineering programmes (in Swedish; together with F Gröndahl) that was published by Liber in 2011.

Marie Arehag Coordinator of the Chalmers Learning Centre, Chalmers University of Technology, marie.arehag@chalmers.se

Chalmers Learning Centre, Lindholmen, SE-412 96 Göteborg, Sweden

Marie Arehag has worked with educational development within Chalmers since the early eighties. The intensions have varied from including environmental aspects to aspects from humanities and social sciences to pedagogical reform work. In recent years, the notion of ESD includes all the precious ambitions. 